\title{
COMPARAÇÃO, HISTÓRIA E TRANSIÇÕES - OS CASOS DE BRASIL E ARGENTINA ENTRE 1979 E 1989
}

\section{Camila Tribess ${ }^{1}$}

Resumo: A partir de 1980 ditaduras foram substituídas por democracias em vários países da América Latina, assim, a questão das transições políticas tornou-se objeto importante na Ciência Política. A principal linha de estudos destaca a importância dos conflitos dentro do regime (entre "duros" e "brandos"), além de fatores como: crise econômica, guerras, mobilização social, pressão internacional etc. Neste trabalho faz-se uma retomada teórica de algumas das explicações, focando-se numa contextualização histórico-comparada. Para o caso do Brasil, o recorte temporal é de 1979 até 1989, ano das "eleições fundacionais". Para o caso argentino, o recorte é de 1980 até o fim de 1983, com a eleição democrática de Raúl Alfonsín. Comparamos o processo de transição argentino, que ocorreu por ruptura, com o processo brasileiro, que foi por transação, buscando compreender as semelhanças e diferenças de ambos os processos.

Palavras-chave: transição política, redemocratização, política comparada, Argentina, Brasil.

Resumen: Desde 1980, las dictaduras han sido sustituidas por las democracias en muchos países de América Latina, por lo tanto la cuestión de las transiciones políticas se convirtió en objeto importante en la Ciencia Política. La principal línea de investigación destaca la importancia de los conflictos dentro del régimen (entre "duros" y "blandos"), junto con factores como la crisis económica, guerras, movilización social, presión internacional etc. En este artículo ofrecemos un resumen de algunas de las explicaciones teóricas, centrándonos en un contexto histórico-comparativo. Para el caso de Brasil, el plazo es desde 1979 hasta 1989, año de las "elecciones fundacionales". Para el caso argentino, el recorte es a partir de 1980 hasta finales de 1983, con la elección democrática de Raúl Alfonsín. Comparamos la transición en Argentina, que se produjo por ruptura, con el proceso brasileño, que fue por transacción, buscando comprender las similitudes y diferencias de ambos procesos.

Palabras-clave: transición política, redemocratización, política comparada, Argentina, Brasil.

Abstract: Since 1980 dictatorships have been replaced by democracies in many Latin America countries, therefore he question of political transitions became important object in Political Science. The main line of research highlights the importance of conflicts within the regime (between "hard" and "soft"), together with factors such as economic crises, wars, social mobilization, international pressure and so on. This article is a summary of some of the theoretical discussions, focusing on a comparative historical context. In the case of Brazil, the period is from 1979 to 1989, the year of "founding elections." For the Argentine case, the cut is from 1980 to late 1983, with the democratic election of Raul Alfonsin. We compare the transition in Argentina, which occurred by rupture, with the Brazilian process, which was per transaction, seeking to understand the similarities and differences of both processes.

Key-words: political transition, democratization, comparative politics, Argentina, Brazil.

\footnotetext{
${ }^{1}$ Graduada em Ciências Sociais e Mestranda em Ciência Política pela Universidade Federal do Paraná. Pesquisadora do Núcleo de Pesquisa em Sociologia Política Brasileira - NUSP, e do Núcleo de Pesquisa em Relações Internacionais - NEPRI.
} 


\section{APRESENTAÇÃO}

A partir de 1980, quando regimes ditatoriais foram sendo substituídos por regimes democráticos em um grande número de países da América Latina, a questão das transições de regimes políticos tornou-se objeto de estudo importante para a Ciência Política e áreas afins. Várias explicações são dadas à dinâmica do processo de transição, que se verificou em vários países e de diversas formas. Uma das principais linhas de estudos destaca a importância dos conflitos dentro do regime, junto com diversos outros fatores, como crise econômica, guerras, mobilização social, pressão internacional etc. (O’DONNEL, G. e SCHMITTER, P. 1988; ROUQUIÉ, A., LAMOUNIER, B. e SCHVARZER, J. 1985; LINZ, J. e STEPAN, A. 1999 etc.).

Diversas associações e organizações (de empresários, políticos, intelectuais, artistas e estudantes) influenciaram nesses processos de transição, bem como a dinâmica econômica, as crises, as pressões externas, guerras e vários fatores políticos, econômicos e sociais podem ser usados como variáveis explicativas das transições.

Neste artigo intentamos compreender a dinâmica política de dois processos de transição numa perspectiva histórica, buscando obter elementos para uma visão ampla do contexto social e político que desencadearam os processos de transição para a democracia. Escolheram-se dois países latino-americanos como base para um estudo comparado, são eles Brasil e Argentina. Para o caso brasileiro o recorte temporal do período que consideramos de transição é de 1979, início do governo de João Figueiredo, até 1989, ano das “eleições fundacionais” (O’DONNEL, G. e SCHMITTER, P. 1988). Para o caso argentino o recorte é de 1980, início da liberalização política, até o fim de 1983, com a eleição democrática de Raul Alfonsín.

Tomamos dois casos que podem ser considerados como casos modelo. Comparamos o processo de transição argentino, que ocorreu por ruptura e de forma rápida, com o processo de transição brasileiro, que foi por transação e durou mais de uma década para concretizar-se. A comparação entre os processos de transição para o regime democrático se explica ao pensarmos que a transição na Argentina durou 18 meses, desde a Guerra das Malvinas até as eleições de 1983 e é, tipicamente, classificada como uma "transição por colapso" (O’DONNELL et all, 1988 p. 25), enquanto que, em contraposição, temos a transição brasileira, que durou cerca de uma década e é classificada como "transição via pactos" (idem p. 22). No primeiro caso há uma queda brusca do regime, já no segundo caso a transição é controlada pela elite do regime e ocorre de forma gradual. Assim, temos o seguinte panorama: ambos os países passaram por um processo de transição de uma ditadura militar para uma democracia, 
porém, em condições completamente diversas, apesar da proximidade geográfica e das semelhanças históricas, culturais e econômicas.

Nesse sentido, os estudos históricos e sobre processos políticos, principalmente em uma perspectiva comparada, dentro da Ciência Política em geral, podem ser extremamente enriquecedores para a compreensão destas diferenças. Além disso, acreditamos que este tipo de estudo favorece a compreensão dos processos políticos e suas dinâmicas nos diferentes países da América Latina, auxiliando nas reflexões sobre o contexto político e social destes países. Assim, é de grande importância para toda pesquisa sobre o tema compreender de forma ampla o processo de transição, antes mesmo de testar qualquer teoria ou hipótese. Este é o papel deste artigo, ser um passo inicial, com estudo histórico.

Buscamos compreender, portanto, as semelhanças e diferenças no processo de transição democrática no Brasil e na Argentina na década de 1980 pelo mapeamento da situação dos respectivos países antes e durante a transição política. Fazemos isso a partir de pesquisa historiográfica e com base na literatura sobre o tema. Nossa hipótese neste artigo é a de que existem diferenças e semelhanças políticas, sociais, econômicas e culturais nos processos de transição democrática nesses dois países que, ao serem analisadas de forma comparada, podem ajudar a entender o diferente timing desenvolvido em ambos os processos.

\section{A PERSPECTIVA HISTÓRICO-COMPARADA E A NECESSIDADE DA COMPARAÇÃO}

A comparação nos permite pensar modelos mais amplos que expliquem situações, causas e fenômenos políticos, além de sublinhar semelhanças e diferenças que podem ser úteis para as reflexões sobre os casos pesquisados. Para Sartori (1994), a comparação é uma maneira de controlar nossas generalizações, que permite pensar em leis do tipo “se..., então...”. Por meio da comparação podemos ter uma visão maior dos problemas e conceitos e, assim, nossos estudos não se encerram em somente um caso ou um país, o que torna as pesquisas mais sólidas e explicativas. Mas, não podemos comparar tudo, ou qualquer caso. Casos muito iguais ou muito distintos dificultam a comparação, o melhor é que possamos seguir os conselhos de J. Stuart Mill (1886, in PERISSINOTTO 2009) comparando casos distintos, mas com o mesmo fenômeno a explicar (no caso da comparação pelo método da semelhança); ou casos com aspectos semelhantes, mas que em alguns casos o fenômeno a ser explicado não ocorra (no método da diferença). 
Para Panebianco (1994), as comparações mais gerais são as que possuem a mesma lógica da comparação estatística, mas, as semelhanças que encontramos não podem ser consideradas toda a explicação de nossos casos. Estas comparações, quando feitas para universos pequenos, são muito importantes e podemos mesclar comparações históricas com comparações estatísticas sempre que possível. No entanto, as comparações históricas são mais complexas e podem nos oferecer maiores resultados explicativos, como aponta Collier (1994), que diz que quando temos somente dois ou três casos a comparar, mas com muitas variáveis, as comparações se tornam mais complexas e com mais profundidade. Sendo assim, o método comparativo é o mais indicado para estudos com poucos casos.

Sartori (1994) nos indica quatro problemas conceituais que ocorrem nos estudos políticos e que devemos tomar em conta. O primeiro deles é o que Sartori chama de "paroquialismo". Este problema ocorre quando os estudos se limitam a apenas um local ou país e se fecham para os outros casos, o que faz as pesquisas se tornarem muito restritas e os conceitos muito parciais. O segundo problema são os "erros de classificação". Isto ocorre quando colocamos casos muito distintos sob um

mesmo conceito, ou seja, quando tentamos explicar coisas muito diferentes com uma única idéia. O terceiro problema é o que Sartori denomina de "gradualismo", ou seja, quando definimos que tudo se baseia na mesma variável e o que muda é apenas o grau, que varia em um continuo. Quando fazemos isto, os pontos de diferenciação são muito arbitrários e, na maior parte dos casos, são postas conforme as necessidades de classificação do pesquisador. Por último, o problema do "alargamento de conceitos", isto ocorre quando os conceitos são utilizados de forma tão ampla que já não podem explicar nada, pois não tem definições certas, mas somente palavras utilizadas para muitos casos distintos. Nesse sentido, Sartori aponta que a comparação pode ajudar o pesquisador a evitar esses erros.

\section{A QUESTÃO DAS TRANSIÇÕES PARA A DEMOCRACIA}

Os estudos comparados sobre as transições democráticas confirmam, em grande parte, o que O’ Donnell e Schmitter (1988) propõem como causas principais das transições, que são: os conflitos dentro e fora do regime; o início de uma liberalização, que faz com que a sociedade civil seja revitalizada politicamente; pactos entre as elites, grupos políticos organizados, forças armadas, empresários e sociedade em geral.

Alguns estudos sobre as transições democráticas (O’DONNEL, G. e SCHMITTER, P. 1988; ROUQUIÉ, A., LAMOUNIER, B. e SCHVARZER, J. 1985; LINZ, J. e STEPAN, A. 1999, entre outros) apontam para duas etapas, uma do término do 
regime autoritário e a outra da "consolidação" da democracia. Estes trabalhos apontam que o porquê das transições não está apenas em uma das partes envolvidas, somente nos “duros" ou nos "brandos" (O’DONNELL et all, 1988), no governo ou na oposição, mas sim, devemos analisar as completas relações que se dão tanto dentro do regime. Além disso, não se pode colocar só as "elites" ou só as "massas" como as responsáveis pela transição, em todos os casos, o processo e as relações se dão em ambos os sentidos. A questão de como ocorrem as transições também é muito importante nos estudos comparados sobre esses processos e parece haver um consenso de que as transições ocorrem por razões mais complexas que simples divisões nos regimes. Assim, para O’Donnell et all (1988) as transições podem ocorrer por diferentes modelos. Por "ruptura" o regime cai e as relações políticas e sociais mudam por completo (como no caso da Argentina). Por "reforma" a transição é lenta e mudam os modelos do regime até a abertura (este foi, por exemplo, o caso do Brasil, em que a transição durou quase 10 anos). Além disso, existem também os modelos intermediários a estes, que podem ser quando as regras do regime não mudam de imediato, ou quando as regras mudam, mas os governantes do antigo regime podem negociar sua saída. Outro aspecto importante é quando ocorre a transição. Vários dos autores tentam definir uma data ou evento específico, mas as explicações ficam em uma relação complexa entre as divisões do regime junto às modificações sociais e os problemas internos do país. Há também a possibilidade de um cálculo de oportunidade pelos governantes mediante as oportunidades na sociedade, mas as explicações ainda não podem precisar porque exatamente os regimes mudam e quando o fazem.

Entretanto, as transições não significam a consolidação ou a institucionalização da democracia. O tipo de regime autoritário que o país teve antes da transição e a dinâmica da transição influi muito no novo sistema político e sua consolidação. Além disso, também os fatores econômicos, as crises e necessidades dos países influenciam na forma com que ocorrem as transições.

Ao consultarmos a principal literatura que se dedica ao estudo das transições políticas no Brasil e na Argentina (O’DONNEL, SCHIMTER e WHITEHEAD, 1988; QUIROGA, 2001; ROMERO, 2004 e FAUSTO e DEVOTO, 2004), tem-se a impressão que esta transição, em ambos os países na época, era, de fato, uma conseqüência de uma complexidade de fatos políticos, econômicos, culturais e sociais. Não cabia, assim, à elite política decidir se faria a transição ou não, mas sim, coube à elite decidir como fazê-la.

O contexto social, econômico, político e cultural teve grande importância no processo de transição, mesmo que as decisões políticas de fato sejam tomadas por uma elite política, esta é também, muitas vezes, pressionada ou influenciada pela 
movimentação social causada por outros fatores. Temos exemplos dessas pressões sociais tanto na Argentina, com as "Madres de La Plaza de Mayo", quanto no Brasil, com o movimento das "Diretas Já", entre outros (QUIROGA, 2001; ROMERO, 2004 e FAUSTO e DEVOTO, 2004).

A transição brasileira foi muito longa e, na fala dos próprios atores da elite política da época: "lenta, gradual e segura". Essa lentidão se deu, em grande medida, pelo controle que o regime teve sobre a transição, controle esse conseguido tanto pelos rumos do regime (um relativo sucesso econômico no primeiro momento) quanto pela histórica falta de mobilização social no Brasil (O'DONNELL, SCHIMTER e WHITEHEAD 1988 - p. 22). Em contraposição, na Argentina esse processo foi relativamente curto e se deu sem praticamente nenhum controle dos membros do regime sobre a transição. Até houve, em certa medida, uma tentativa dos militares de negociarem sua saída do poder, o que se mostrou infrutífero já que a queda do regime era previsível a todos, principalmente após grave crise econômica e à derrota em uma guerra externa (CAVAROZI, 1988; FAUSTO e DEVOTO, 2004; PALERMO e NAVARO, 2007). Seguindo este raciocínio, apresentamos a seguir a contextualização histórica desses dois casos específicos, para embasar nossas comparações entre as duas transições.

\section{A TRANSIÇÃO NA ARGENTINA}

É difícil se precisar no tempo ou em um fato histórico exatamente quando ocorrem as transições, por isso, normalmente se definem uma série de acontecimentos que podem simbolizar e marcar temporalmente a transição, que em alguns casos dura poucos meses (ou até dias) e em outros casos pode durar mais de uma década.

Na Argentina - depois da dura repressão dos anos 1976/1978 - no início do ano de 1980 a oposição começou novamente a se manifestar, o plano econômico dos militares para a Argentina já demonstrava sinais de pleno fracasso e no fim de 1980 ressurgiu a CGT (Confederación General del Trabajo) e os líderes partidários (do Partido Justicialista, PJ e da União Cívica Radical, UCR, principalmente), reapareceram na cena política. Além disso, se seguiram na presidência militar do país o general Roberto Eduardo Viola, depois Leopoldo Fortunato Galtieri que, em 1982 iniciou o processo da guerra das Malvinas e, rapidamente, perdeu a guerra contra a Inglaterra em junho de 1982. Aqui, então, o processo de transição tornou-se claro (FAUSTO e DEVOTO, 2004 p. 457/458). Quando o general Reynaldo Bignone assumiu a presidência no mês seguinte (julho de 1982), já pode ser considerado um governo de transição não-civil. Convocou eleições livres e diretas para o ano seguinte, em outubro 
de 1983, em dezembro do mesmo ano, 18 meses após o fim da guerra das Malvinas, a Argentina já era governada novamente por um presidente civil eleito diretamente. As eleições levaram ao poder Raúl Afonsín da UCR (LINZ e STEPAN, 1999; FAUSTO e DEVOTO, 2004; ROMERO, 2001; PALERMO e NAVARO, 2007). Para Linz e Stepan (1999), uma transição de 18 meses não pode ser considerada um "colapso", como argumentam O’Donnel, Schmiter e Whitehead (1988, p. 25). Não houve um governo provisório civil e as forças armadas estavam tão fragmentadas que não conseguiram impor nenhuma pauta aos partidos políticos. Não houve, portanto, um pacto na transição argentina, entretanto, para estes autores, também não se pode falar em um colapso, mas, de qualquer forma, a transição argentina foi muito mais rápida que a brasileira e com uma dinâmica bem diversa.

\section{REGIME E OPOSIÇÃO}

No dia 24 de março de 1976 os comandantes Jorge Rafael Videla, Emilio Eduardo Massera e Orlando Ramón Agosti deram um golpe de Estado na Argentina. O golpe foi chamado de "Processo de Reorganização Nacional" e Videla foi o presidente até 1978. Os militares implementaram um programa que se colocava como a solução dos conflitos na sociedade argentina, trazendo o monopólio da violência unicamente para o Estado. Essa violência seria fortemente usada para exterminar o conflito na sociedade. Houve cerca de 9 mil casos de "desaparecidos" confirmados e investigados, mas as comissões de direitos humanos avaliam em 30 mil o número correto. Isso tudo em apenas 3 anos de repressão pesada (1976/1978), depois disso, a partir de 1980 já se pode considerar um período de transição. As organizações de milícia de esquerda, como os "Montoneros", foram dizimadas, mas mesmo depois disto a violência se estendeu a diversos líderes sindicais, religiosos, advogados, militantes de direitos humanos, intelectuais e líderes políticos em geral.

Todos os partidos, sindicatos, agremiações e qualquer atividade de cunho político foram proibidas, além da repressão contra artistas, escritores, intelectuais e contra a imprensa. Assim, apenas a voz do Estado existia contra os indivíduos isolados. O ideal autoritário foi, na maioria das vezes, internalizado e instaurou-se a cultura do medo. O denuncismo e o ostracismo eram recorrentes. Romero (2008) argumenta que em nenhum momento, nem mesmo na copa do mundo de futebol (1978), em que a Argentina foi campeã, o regime logrou alcançar adesão da população. O Estado argentino tornou-se inoperante, corrupto e fragmentado, já que as 3 armas dividiram entre si cargos, ministérios e funcionários, fazendo com que o aparelho estatal fosse paralisado por jogos de poder e falta de um controle estipulado. Nem mesmo o 
presidente e sua função escaparam a essa divisão, já que com a formação da junta militar o poder daquele estava limitado pela atuação desta.

O grupo mais extremista dentro das forças armadas, formado basicamente por Luciano Benjamín Menéndez, Carlos Suárez Mason e Ramón J. Camps defendiam que a repressão (que eles comandavam) deveria seguir até as últimas conseqüências. Estavam assim, em conflito permanente com o grupo de Videla e, principalmente, de Viola.

As disputas internas foram acirradas pelo comando da presidência e das forças armadas, bem como várias negociações que permitiram Viola assumir o governo, mas que também fizeram com que ele fosse aposentado forçadamente e Galtieri assumisse o poder. No breve governo de Viola os empresários, que durante longo período estavam fragmentados e desconfiados do governo militar, foram incluídos no governo, mas essa inclusão acabou junto com o governo de Viola. Assim, os empresários, muito afetados pela crise econômica, apoiaram, cada vez mais fortemente, a oposição ao regime. De 1976 até abril de 1979 os sindicatos foram subjugados à inexistência de fato, só existiam formalmente, já que seus líderes foram presos, as greves proibidas e as negociações salariais encerradas (cf. PALERMO e NAVARO, 2007). Apenas em 1979, quando o regime dava seus primeiros suspiros de cansaço, é que os sindicalistas extremistas conseguiram organizar uma greve geral, a qual os moderados não acataram, essa paralisação acabou com muita repressão e várias prisões. Já no final de 1980 os sindicalistas retomaram a CGT, elegendo Saúl Ubaldini como secretário geral, um membro pouco conhecido na época. Em 1981 a CGT organizou nova paralisação geral, recebendo mais repressão e no fim de 1981 (novembro) fez uma marcha pedindo "pão, paz e trabalho", sendo apoiados por alguns empresários e pelos estudantes. A partir desse período as greves e paralisações começaram a surgir mais amiúde, culminando, em 30 de março de 1982, em uma manifestação na Plaza de Mayo, que o governo reprimiu fortemente, com cerca de 2 mil presos em Buenos Aires.

As "Madres de la Plaza de Mayo", utilizando o apelo da maternidade e da família, que não podiam ser negadas pelos militares nem colocadas como subversivas, logo se tornaram o centro do questionamento ao regime, sendo foco de atenção inclusive no exterior, com um apelo comovente e que colocava em pauta a repressão que os militares queriam esconder. Segundo Romero (2008, p. 228),

\footnotetext{
"Desde o fim de 1981 os militares se viram obrigados a dar alguma resposta a um tema que pretendiam arquivar sem discussão [o tema dos desaparecidos], e ainda que de forma geral tenham coincidido que a questão deveria ser encerrada, mostraram diferenças e contradições que aprofundaram suas dissensões anteriores e ampliaram um pouco mais a brecha por onde a opinião pública, largamente calada, começava a reaparecer".
} 
Assim, os movimentos de oposição ganhavam fôlego. As "Madres de La Plaza de Mayo" ganharam, aos poucos, repercussão internacional, colocando o tema dos desapareciemntos e da tortura em discussão, exatamente como os militares não queriam, o que enfraqueceu ainda mais o Regime. Com os conflitos internos entre os próprios militares, não havia coesão de pensamento, discurso e atuação, fazendo com que a sociedade legitimasse ainda mais os movimentos contra a ditadura.

Em 1981 acabou a proibição aos partidos e a Organização Multipartidária foi formada por peronistas, radicais e pequenos partidos - apesar de frágil e sem líderes (ou com os mesmo líderes de 1975), essa organização se comprometeu a não colaborar com o regime e não aceitar uma democracia tutelada. Junto com os demais movimentos que tomavam fôlego, até 1982 a oposição cresceu e fez-se notar.

Desde 1980 os militares buscavam uma saída política, mas com as divisões internas, que se agravaram na presidência de Viola, a qual a marinha se opôs. Viola começou o diálogo com a sociedade - principalmente empresários - e preocupava-se com uma eventual transição política. Mas não obteve sucesso nem em deter a crise, nem em negociar com a sociedade. No final de 1981, Viola adoeceu e foi retirado do cargo por seus opositores e assumiu a presidência o general Leopoldo Fortunato Galtieri, que era também comandante em chefe das forças armadas, quebrando assim uma regra imposta pelos próprios militares (não acumulação desses 2 postos). Galtieri não tinha manejo político, mas havia passado tempos nos Estados Unidos e apontava para laços estreitos com esse país, o que lhe garantia uma imagem de alguém que poderia "salvar" o Processo. Seu ministro da economia foi Roberto Alemann, que aprofundou a crise, transbordando os protestos de empresários e sindicatos. Alemann anunciou um programa de privatizações (inclusive do subsolo) que despertou a contrariedade dos próprios militares. Assim, o governo Galtieri encontrou enorme resistência, culminando com uma grande manifestação da CGT em março de 1982 (cf. PALERMO e NAVARO, 2007, LINZ e STEPAN, 1999; FAUSTO e DEVOTO, 2004; ROMERO, 2001).

\section{MALVINAS}

Nesse contexto, volta à tona o conflito com a Grã-Bretanha pela questão das ilhas Malvinas, que existia desde 1833, mas que nunca havia sido priorizada, pela força do oponente e pela impossibilidade de a Argentina agir de fato nesse setor. Com Galtieri e o suposto apoio dos Estados Unidos essa idéia parecia a solução para vários problemas: a unificação das forças armadas para um objetivo comum; a conquista da 
legitimidade do regime pela obtenção de um reclamo antigo da população; a conquista de passagem para o Pacífico - perdida no conflito com o Chile em 1978. Além disso, não passava pelos planos militares uma guerra, mas apenas uma ocupação, com o apoio efetivo dos Estados Unidos e então uma negociação com a Inglaterra.

A ocupação ocorreu em 2 de abril de 1982, com o exército argentino vencendo poucas tropas de defesa da Inglaterra que ficavam nas ilhas. Após esse fato e de uma visita do secretário de Estado estadunidense houve uma ampla adesão social à iniciativa.

No entanto, a guerra era contra a Grã-Bretanha de Margareth Tatcher, que precisava tanto quanto os militares argentinos de legitimação, além do que, a ala belicista e conservadora do governo calou facilmente os pacifistas ingleses. A reação contra a Argentina veio dura. A Inglaterra teve apoio da comunidade européia e da Organização das Nações Unidas (ONU), foram postas severas sansões econômicas à Argentina e ela foi considera nação agressora. Os Estados Unidos se retiraram das negociações com o começo dos ataques ingleses e colocou sansões à Argentina, também oferecendo apoio logístico à Inglaterra. A guerra começou, mas as informações que chegavam à população argentina eram apenas de vitórias. A oposição, nesse momento, já colocava a questão de um governo de transição no pós-guerra, principalmente a União Cívica Radical e seu líder, Raúl Alfonsín. Em 14 de junho a Argentina foi vencida e o governo comunicou a rendição, que deixou mais de 700 mortos. Os militares exigiam a renuncia de Galtieri, como se ele houvesse sido o único responsável pela derrota.

\section{A TRANSIÇÃO E O COLAPSO}

Com o fim da guerra as falhas e cisões do regime se tornaram ainda mais evidentes. A junta militar foi responsabilizada pela derrota, a marinha e a aeronáutica se retiraram da junta e o exército impôs o sucessor de Galtieri, o general Reynaldo Bignone. O governo militar propôs a saída eleitoral, mas queria assegurar que sua saída do governo não seria "um desbande" (ROMERO, 2008 p.235). O governo militar tentou então negociar uma série de questões: políticas econômicas, presença das forças armadas no próximo governo, e, principalmente, a garantia de não investigação de corrupção, enriquecimento ilícito, seqüestros, desaparecidos e torturas (a "guerra suja" como denominavam os militares). Essas negociações foram divulgadas pela imprensa, que retomava sua atividade sem censura e de forma sensacionalista, em novembro de 1982 e logo rechaçada pela opinião pública e pela Multipartidária, que tinha como único fio condutor o de não colaborar com o regime. A Multipartidária convocou uma 
grande manifestação pela democracia, que fez com que os militares marcassem as eleições para o final de 1983. A oposição crescia e a mobilização popular era cada vez mais forte, as denúncias das prisões, torturas e assassinatos cresciam a cada dia (cf. LINZ e STEPAN, 1999; FAUSTO e DEVOTO, 2004). Enquanto isso as forças armadas se dividiam e enfraqueciam por seus conflitos internos cada vez mais. As alianças antigas já eram irretomáveis e os crimes do passado tornavam explícita a ilegitimidade do regime perante ele mesmo.

Os partidos, organizações de estudantes e movimentos sociais e sindicais cresciam vigorosamente, a CGT recuperava os sindicatos que estavam sob intervenção estatal, entre 1982 e 1983 diversas manifestações e paralisações foram feitas. No entanto, não havia mais um grande líder, como havia existido nos anos peronistas, a saída política era de conciliação. A esperança democrática contagiava a todos, quando os partidos voltaram à legalidade, cerca de $1 / 3$ da população eleitoralmente ativa se filiou a algum partido, isso não apenas deu fôlego às discussões políticas como também renovou lideranças e formas de fazer e pensar política na Argentina. Essa renovação se deu inclusive no peronismo (tradicionalmente não democrático), mas alguns líderes antigos continuavam em cena, como o sindicalista Lorenzo Miguel e Hermínio Iglesias. O candidato a presidência do peronismo foi Ítalo Luder, jurista que unia as forças novas e tradicionais do partido. Já o radicalismo tinha como líder Raúl Alfonsín, que esteve a frente da oposição ao regime desde o início e com seu discurso e atitude fez crescer a importância da União Cívica Radical (UCR). Assim, novamente, UCR e Partido Justicialista (PJ) predominaram na cena política argentina das novas eleições. Alfonsín conquistou a população com seu discurso democrático e renovador, prometendo negociações com todas as demandas sociais e responsabilização dos militares por seus crimes, assim, ganhou as eleições dos peronistas, que nunca haviam perdido, a não ser para os diversos golpes militares que sofreram desde 1930 (cf. ROMERO, 2001).

\section{A TRANSIÇÃO NO BRASIL}

O momento de abertura política no Brasil, ou de "liberalização" (O’DONNELL, SCHIMTER e WHITEHEAD 1988; MARTINS, 1988, LINZ e STEPAN, 1999 etc.) ocorreu a partir do governo de Ernesto Geisel, ainda em 1974, no entanto essa liberalização foi parcial e muito restrita (DAHL, 1997 p. 56). Em 1977 há um grande retrocesso nesse processo de liberalização, com o recesso da Câmara dos Deputados e o Pacote de Abril, a Lei Falcão, de 1976 é estendida e os Senadores Biônicos formam 1/3 do senado. Nesta pesquisa consideraremos, portanto, que a transição política para um 
regime democrático se inicia de fato no Brasil apenas em 1979. Com a volta do pluripartidarismo, a lei de anistia e o fim do Ato Institucional no. 5 (censura) é que podemos considerar que a abertura política da ditadura de fato avança e torna-se quase irrevogável (FAUSTO e DEVOTO, 2004).

No Brasil, o primeiro presidente civil é eleito por vias indiretas, em 1985, 6 anos depois da lei de anistia e 11 anos depois do início do processo de liberalização (1974). Entretanto, apenas em 1989 é que há eleição livre e direta para um presidente civil, encerrando assim o ciclo da transição de regime político (FAUSTO e DEVOTO, 2004; DINIZ, BOSCHI e LESSA, 1989). Para Linz e Stepan (1999, p.21) a transição no Brasil só se completaria com o governo Collor (eleições livres, governo de fato etc.), no entanto, consideramos aqui que o processo de transição ocorre até o momento das eleições de 1989, sem incluir o governo Collor como um todo.

\section{REGIME E OPOSIÇÃO}

Em $1^{\circ}$. de abril de 1964 os militares brasileiros tiraram do poder o presidente João Goulart e instauraram a ditadura militar. Entre os anos de 1964 e 1987 vários generais se sucederam na presidência da república. Ao contrário da Argentina, no Brasil os militares nunca haviam governado através de uma ditadura, eles já haviam sido instrumento de outros golpes, como em 1930, mas nunca haviam instaurado uma ditadura militar de fato. Esse governo foi assim instaurado por um ato institucional em 9 de abril de 1964, houve a cassação de vários mandatos nesse período. Em 1965 foi instaurado o bipartidarismo. As eleições nesse período foram mantidas parcialmente, mas controladas pela ditadura militar, havendo um partido de oposição legal, o MDB (Movimento Democrático Brasileiro) e o partido de apoio ao regime, ARENA (Aliança Renovadora Nacional).

Em 1966 foi promulgado o Ato Institucional $n^{0} 5$, que limitava de forma intensa as liberdades individuais de expressão e de imprensa. Vários funcionários públicos e políticos (professores universitários, prefeitos, governadores, deputados etc.) foram destituídos de seus cargos ou cassados, todo tipo de manifestação era duramente reprimida e com o passar do tempo e os vários atos institucionais que foram executados, as prisões por motivos políticos se multiplicaram.

A ditadura brasileira, a princípio, não se caracterizou por uma violência tão explícita quanto a ditadura argentina (que foi uma das mais violentas do continente), mas ainda assim foi marcada por prisões, desaparecimentos e torturas. Alguns autores (cf. PEREIRA, 2010 e FAUSTO e DEVOTO, 2004) apontam para o fato de que a oposição no Brasil não era tão organizada e combativa quanto na Argentina, com 
algumas exceções marcantes, como a guerrilha do Araguaia, que foi brutalmente exterminada, bem como grupos de guerrilha urbana, como o liderado pelo ex-deputado Carlos Marighella. A violência no Brasil, inclusive a tortura, foi mais institucionalizada e legitimada pelo regime e não feita de forma clandestina como na Argentina, mas isso não exclui a existência de inúmeros registros de "desaparecidos".

\section{LEGITIMAÇÃO E PROCESSO DE LIBERALIZAÇÃO}

Em 1967 foi promulgada a nova Constituição brasileira que oficializava alguns artifícios de governo, tais como os "senadores biônicos" (senadores indicados diretamente pelos militares e com mandato vitalício) e as indicações do poder executivo federal para governadores dos estados. As eleições diretas para a Câmara dos Deputados foram mantidas, apesar de serem muito restritas, já que serviam para manter sob controle as elites regionais, além de legitimar socialmente o regime.

A combinação de: censura; grande crescimento econômico alcançado pelo regime com o chamado "milagre brasileiro"; abstenção de grande parte da oposição nas eleições; apoio das elites regionais, que estavam inseridas nos postos de governo ou nas eleições legislativas; entre outros fatores, garantiram a legitimação do regime nas urnas, até o ano de 1974, ano em que a oposição começou a se fortalecer. Nestas eleições a oposição conseguiu uma relevante vitória nas eleições legislativas e o general Ernesto Geisel assumiu a presidência com um discurso de liberalização. No entanto, essa liberalização foi contraditória. A cada avanço em determinado aspecto, havia um retrocesso em outros, com formas alternativas de manipulação pelo regime. Isso só foi possível pelo grande controle sobre o processo de transição que o regime exerceu e foi também esse controle que possibilitou que o regime guiasse as eleições seguintes. Com diversos artifícios, leis, decretos e ferramentas de controle, sendo os mais conhecidos a Lei Falcão (1976) e o Pacote de Abril (1977), que limitavam as possibilidades da oposição ter representantes eleitos e, inclusive, de fazer campanha política. O regime garantiu assim sua legitimação através das urnas.

A partir de 1979 é que podemos considerar que há, de fato, um início de abertura do regime, com a lei da anistia, a volta do pluripartidarismo, eleições diretas para governadores dos estados e a extinção do cargo de senador biônico. Neste ano, assumiu a presidência o general João Figueiredo, indicado após um processo de negociações entre os grupos "duros" e "brandos" do regime. Figueiredo assume com a promessa de democratização, concede anistia aos presos e exilados políticos e permite a criação de novos partidos, buscando fragmentar a oposição. Surgiram então o PFL (Partido da Frente Liberal), de um racha da base do regime, o PDT (Partido 
Democrático Trabalhista), o PTB (Partido Trabalhista Brasileiro), o PT (Partido dos Trabalhadores) e o MDB se tornou PMDB (Partido do Movimento Democrático Brasileiro), todos estes na oposição ao regime. O partido da base do regime tornou-se PDS (Partido Democrático Social). Prorrogaram-se as eleições que aconteceriam em 1980 e houve repressão ao Congresso Nacional, que buscava recuperar certas prerrogativas legislativas. Seguiu-se o processo de abertura controlada. O maior objetivo do regime era uma transição "lenta, gradual e segura" (esse era, inclusive, seu slogan).

Ao final de 1982, com uma séria crise econômica e denúncias de corrupção, afloram as crises internas do regime. A ditadura havia sido até este ponto relativamente estável, entretanto, as críticas crescem, inclusive dentro do próprio regime, acelerando o processo de abertura. Assim, em 1985, o regime mudou as regras de composição do colégio eleitoral que elegeria o próximo presidente da república, sobrerepresentando os estados agrários, nos quais havia uma forte dominação do PDS, garantindo a maioria nas eleições presidenciais de 1985. Entretanto, com a grande crise interna no regime e as dissidências fortemente organizadas na Frente Liberal (futuro Partido da Frente Liberal - PFL), o Colégio Eleitoral elegeu Tancredo Neves como o primeiro presidente civil desde 1964 (o candidato do partido de oposição, PMDB), tendo como vice José Sarney, dissidente do regime. Apesar de uma grande mobilização pelas eleições diretas, manifesta no movimento das "Diretas Já!”, o primeiro governo civil foi eleito de forma indireta, via colégio eleitoral. Além disso, por motivo de doença, Tancredo Neves morre antes de assumir a presidência, assumindo o governo o vice, José Sarney, que antes era apoio político da ditadura militar. Em 1986 foram convocadas eleições diretas para representantes na Assembléia Constituinte, que foi instaurada a partir de 1987 e promulgou a nova constituição em 1988. Assim, o Brasil só pôde ser considerado de fato uma democracia em 1989, com as primeiras eleições democráticas e diretas para presidência, culminando com a eleição de Fernando Collor de Mello.

\section{POSSÍVEIS REFLEXÕES SOBRE OS PROCESSOS DE TRANSIÇÃO}

Temos, a partir dessa breve revisão histórica - que esperamos, tenha auxiliado para uma melhor percepção do contexto das transições políticas - alguma noção das semelhanças e diferenças dos dois processos de transição aqui pesquisados. Podemos resumir as semelhanças ao fato de que ambos os regimes se deram num contexto de crise econômica e que buscavam acabar com os conflitos acirrados na sociedade e eliminar a oposição, principalmente a de cunho comunista. Além disso, percebemos que nos dois países a oposição demorou até se reerguer dos ataques deferidos pelos 
militares às organizações partidárias e aos seus líderes. As organizações que se opunham ao regime começam a ganhar força e legitimidade apenas por volta de 1980, nos dois casos, e precisam se readaptar ao sistema político, fortemente modificado pelas ditaduras. A censura foi fato recorrente em ambos os regimes, nos dois países escritores, cantores, professores e diversos artistas e jornalistas precisaram sair do país para escaparem das prisões e torturas. A vigilância à escolas e universidades também era recorrente. No Brasil, diversos espiões se infiltravam nas salas de aula, na Argentina, vários livros eram levados às fogueiras.

Nesse sentido, podemos apontar as diversas diferenças encontradas nos processos em questão. A começar pela forma com que os regimes se impuseram. No Brasil a ditadura buscou manter uma cortina de legitimidade, mantendo eleições e partidos, além dos poderes legislativos, ao contrário do regime argentino, que eliminou essas instancias. No entanto, essa cortina de legitimidade forjada pela ditadura brasileira não ameniza o fato de que em ambos os países a tortura, as perseguições e violências foram recorrentes. Nesse sentido, podemos afirmar que a violência na Argentina, não assumida pelo Estado militarizado, mas praticada por ele, foi mais incisiva que a brasileira, talvez pelo fato de que a oposição armada na Argentina fosse muito mais representativa que a existente no Brasil. No entanto, é importante lembrar que a violência se estendeu aos civis, não militantes e, inclusive, políticos e clérigos.

Quanto ao contexto econômico, podemos observar que a ditadura militar brasileira alcançou uma certa estabilidade social e política porque logrou manter, por mais tempo, o plano econômico sob controle. Houve nos dois países a ilusão de um "milagre econômico", que na Argentina durou por pouco tempo, já no Brasil foi mantida, à custa de grandes endividamentos do Estado. Na Argentina a crise econômica da década de 1970, principalmente a crise do petróleo, ressonou de forma mais ríspida na economia, fazendo com que a ditadura militar arcasse também com a insatisfação econômica da população. Já esta população sofria com a crise, agravada, sem dúvida, por um aparelho estatal incompetente e crivado de disputas entre as correntes das forças armadas. No Brasil a crise só atingiu a reputação da ditadura já no início da década de 1980, auxiliando, sem dúvida, a oposição a ganhar a simpatia e apoio da população, que sofria com índices muito altos de inflação.

A ditadura argentina também perdeu muito de sua legitimidade - sendo esse, certamente, um dos fatores mais importantes para a ruptura que ocorreu no regime com a guerra das Malvinas. Esse conflito, além de deixar um saldo grande de mortos entre os soldados que foram enviados, não trouxe nenhum benefício ao país, ao contrário, com esse conflito a Argentina sofreu com embargos econômicos e políticos 
de diversos países. Essa guerra, que começou no intuito do regime de obter aprovação junto à população, acabou sendo o fator catalisador da queda da ditadura militar.

O Brasil não passou por conflitos externos, seus conflitos internos não eram tão radicalizados como os que ocorriam na Argentina e isso propiciou à ditadura brasileira um maior controle do processo de transição. Enquanto na Argentina a Multipartidária, as comissões pelos direitos humanos e as Madres de La Plaza de Mayo não permitiam uma negociação com os militares, aproveitando a conjuntura de crise para, não só retomar a democracia, como também garantir a punição dos ditadores e torturadores; no Brasil a oposição negociou o tempo todo, ao mesmo tempo que os militares abriam o regime, sem no entanto, perderem seu poder. A proposta de uma transição "lenta, gradual e segura" se consolidou com a atuação dos generais da ditadura e seus colaboradores, não havendo um momento sequer em que a oposição conseguisse de fato uma vitória completa, todas as vitórias em direção à democracia foram parciais, isso estando explícito na eleição do primeiro presidente civil do período, sendo uma eleição ainda indireta e com forte controle dos militares, apesar da grande pressão popular com o movimento "Diretas Já" e da força da oposição, verificada na vitória de seu candidato.

\section{REFERÊNCIAS BIBLIOGRÁFICAS}

CAVAROZI, Marcelo. Ciclos políticos na Argentina a partir de 1955, in. O'DONNELL, G., SCHMITTER, P. \& WHITEHEAD, L. (orgs.). Transições do regime autoritário: América Latina. Capítulo 4. São Paulo: Vértice, 1988.

CODATO, Adriano N. (ed.). Political Transition and Democratic Consolidation: Studies on Contemporary Brazil. New York: Nova Science Publishers, 2006.

. Uma história da transição brasileira: da ditadura militar à democracia. Revista de Sociologia e Política, $\mathrm{n}^{0}$ 25, 2005.

COLLIER, David. El método comparativo: dos décadas de cambio, in. Sartori, G y Morlino, L. La comparacion en las ciencias sociales, Alianza: Madri, 1994.

DAHL, Robert. Poliarquia: Participação e Oposição. São Paulo: UNESP, 1997.

DINIZ, Eli; BOSCHI, Renato e LESSA, Renato. Modernização e Consolidação Democrática no Brasil: dilemas da nova república. São Paulo: Vértice, 1989.

FAUSTO, Boris e DEVOTO, Fernando J. Brasil e Argentina: um ensaio de história comparada. São Paulo: editora 34, 2004.

LINZ, Juan J. e STEPAN, Alfred. A transição e consolidação de democracia, a experiência do sul da Europa e da América do Sul. São Paulo: Paz e Terra, 1999.

MARENCO DOS SANTOS, André. Despacio se llega lejos? La transición para la democracia en el Brasil en perspectiva comparada. In: Alcántara Saéz, Manuel; Melo, 
Carlos Ranulfo. (Org.). in. La Democracia brasileña: balance y perspectivas para el siglo XXI. Salamanca: Ediciones Universidad Salamanca, 2008.

Para não levar perro-gato por lebre. O que realmente aprendemos comparando países. Porto Alegre: Humanas, 1997.

MARTINS, Luciano. La 'liberalización' del gobierno autoritario en Brasil. in. O’DONNELL, G., SCHMITTER, P. \& WHITEHEAD, L. Transiciones desde un gobierno autoritario. Tomo 2. América Latina. Capítulo 4. Barcelona: Ediciones Paidós, 1994.

MUNCK, Gerardo. La democratizacion en perspectiva comparada. El debate contemporáneo, in. Revista Desarrollo Economico: Buenos Aires, 1996.

O'DONNEL, G.; SCHMITTER, Philippe. Transições do regime autoritário: primeiras conclusões. São Paulo: Vértice, 1988.

O’DONNELL, G., SCHMITTER, P. \& WHITEHEAD, Laurence. (orgs.). Transições do regime autoritário: América Latina. São Paulo: Vértice, 1988.

O’DONNELL, Guillermo - Delegative Democracy? Grupo de Estudos Políticos CEBRAP: working papers, 1994. Acesso em 16/09/2009, 02:40h. Disponível em: http://kellogg.nd.edu/publications/workingpapers/WPS/172.pdf.

PALERMO, Vicente e NOVARO, Marcelo. A Ditadura militar argentina 19761983: do golpe de Estado à restauração democrática. São Paulo: UNESP, 2007.

PANEBIANCO, A. Comparacion y explicación, in. Sartori, G. y Morlino, L. La comparación en las ciencias sociales, Alianza: Madri, 1994.

PEREIRA, Anthony W. Ditadura e repressão. São Paulo: Paz e Terra, 2010.

PERISSINOTTO, Renato M. Comparação e Ciência Social: modelos teóricos e aplicações práticas. In: Colóquio Política, História e Sociedade (anais do evento), Curitiba: UFPR, 2009.

QUIROGA, H. El tiempo del 'Proceso' - conflictos y coincidencias entre políticos y militares, 1976-1983. Introdução e $4^{\mathrm{a}}$ parte. Rosário: Ediciones Homo Sapiens, 2004.

ROMERO, Luis Alberto. Breve historia contemporânea de La Argentina (1916/1999). Buenos Aires: Fondo de Cultura, 2001.

ROUQUIÉ, Alain, LAMOUNIER, Bolivar e SCHVARZER, Jorge. Como renascem as democracias. São Paulo: Editora Brasiliense, 1985.

SARTORI, Giovani. La Politica (cap. 9), Fondo de cultura economica: México, 2002.

Comparación y método comparado. In: SARTORI, G. e MORLINO, L. (ed.).

La comparación en las ciencias sociales. Madri: Alianza, 1994. 